\title{
Salmon in Combination with High Glycemic Index Carbohydrates Increases Diet-Induced Thermogenesis Compared with Salmon with Low Glycemic Index Carbohydrates-An Acute Randomized Cross-Over Meal Test Study
}

\author{
Lone V. Nielsen ${ }^{1}\left(\mathbb{D}\right.$, Signe Nyby ${ }^{1,2}$, Lars Klingenberg ${ }^{1}$, Christian Ritz ${ }^{1}{ }^{1}$, \\ Ulrik K. Sundekilde ${ }^{3} \mathbb{D}$, Hanne C. Bertram ${ }^{3} \mathbb{D}$, Margriet S. Westerterp-Plantenga ${ }^{4} \mathbb{D}$, \\ Bjørn Liaset ${ }^{5}$, Karsten Kristiansen ${ }^{2}$, Lise Madsen ${ }^{2,5} \mathbb{D}$ and Anne Raben ${ }^{1, *} \mathbb{C}$ \\ 1 Department of Nutrition, Exercise and Sports, University of Copenhagen, 1958 Frederiksberg C, Denmark; \\ lvn@nexs.ku.dk (L.V.N.); sherby@live.dk (S.N.); lakl@nexs.ku.dk (L.K.); ritz@nexs.ku.dk (C.R.) \\ 2 Department of Biology, University of Copenhagen, 2100 København Ø, Denmark; KK@bio.ku.dk (K.K.); \\ Lise.Madsen@hi.no (L.M.) \\ 3 Department of Food Science, Aarhus University, 5792 Aarslev, Denmark; uksundekilde@food.au.dk (U.K.S.); \\ hannec.bertram@food.au.dk (H.C.B.) \\ 4 NUTRIM School of Nutrition and Translational Research in Metabolism, Maastricht University, \\ 6229 ER Maastricht, The Netherlands; m.westerterp@maastrichtuniversity.nl \\ 5 Institute of Marine Research, 5005 Bergen, Norway; Bjorn.Liaset@hi.no \\ * Correspondence: ara@nexs.ku.dk; Tel.: +45-2130-6912
}

Received: 8 January 2019; Accepted: 31 January 2019; Published: 10 February 2019

\begin{abstract}
The study investigated the acute effects of meals containing either salmon or veal in combination with carbohydrates with high or low glycemic index (GI) on diet-induced thermogenesis (DIT) (primary endpoint), appetite sensations, and energy intake (EI). Twenty-five overweight men and women ingested four iso-caloric test meals: salmon with mashed potatoes (high GI) (SM), salmon with wholegrain pasta (low GI) (SP), veal with mashed potatoes (VM) and veal with wholegrain pasta (VP). Energy expenditure was measured in the fasting state and six times postprandially for 25 min with 5-min breaks between each measurement. Appetite sensations were measured every $30 \mathrm{~min}$. Blood samples, from arterialized venous blood, were drawn every 20 min until an ad libitum buffet-style lunch was served $3.5 \mathrm{~h}$ later. DIT was $40 \%$ higher after the SM meal compared to the SP meal $(p=0.002)$. Prospective food consumption was lower after the SM meal compared with the VP meal $(p=0.01)$. There were no differences in satiety, hunger, fullness, or ad libitum EI between the test meals (all $p>0.05$ ). In conclusion, salmon with high GI carbohydrates increased DIT compared to salmon with low GI carbohydrates. This indicates that DIT is sensitive to the GI of the carbohydrates after intake of salmon but not veal.
\end{abstract}

Keywords: protein; fish; meat; appetite; amino acids; ghrelin; glucose; energy expenditure; energy intake; mixed meals

\section{Introduction}

High protein diets increase diet-induced thermogenesis (DIT) and satiety compared with low protein diets [1-4]. As proteins have unique characteristics depending on the amino acid composition and absorption rate, it has been speculated whether proteins from different sources affect DIT and appetite differently. Studies on the impact of different protein sources on DIT are sparse, whereas the 
impact on appetite is more investigated [5-12]. However, the lack of adequate standardization and the use of different types of protein meals complicate the interpretation of these studies.

Health authorities recommend the general population to consume seafood, particularly oily fish, in order to reduce the risk of cardiovascular diseases [13]. Fish and seafood are the main dietary contributors to marine n-3 polyunsaturated fatty acids (PUFA), but fish also contains vitamin D, selenium, iodine, and high-quality proteins, all being crucial nutrients [13]. Protein from different fish sources has been shown to increase satiety and reduce ad libitum energy intake (EI) compared with animal proteins (beef, chicken, egg, or turkey) [5-8]. However, the majority of these studies have methodological shortcomings such as a varying protein content between the tested protein sources [6], texture differences and lack of information regarding weight of the test meals [5], or use of liquid test meals, which may not reflect the effect of foods in solid form $[7,14]$.

The glycemic index (GI) is a ranking of carbohydrates according to their effect on blood glucose responses [15]. The majority of the human studies which have investigated the effect of GI on DIT have not shown any effect [16-20]. However, compared to a diet with fish oil in combination with high GI carbohydrates, mice fed a diet with fish oil in combination with low GI carbohydrates had increased oxygen consumption and carbon dioxide production in the fed state [21]. This indicates that the type of carbohydrate in meals with fish oil could influence the thermic response of the meal. The acute effect of mixed meals with low and high GI carbohydrates on appetite and EI has been investigated in numerous human studies [22-24]. However, the evidence for a reduced appetite and EI after meals with low compared with high GI carbohydrates is not convincing.

The objective of the current study was to investigate the acute effects of meals containing salmon versus veal in combination with carbohydrates with high or low GI on DIT (primary endpoint), appetite and EI, as well as postprandial responses of ghrelin, plasma amino acids, glucose, and insulin. We hypothesized that salmon in combination with low GI carbohydrates would increase DIT compared to salmon in combination with high GI carbohydrates or veal in combination with carbohydrates with low or high GI.

\section{Materials and Methods}

\subsection{Study Design}

This randomized, 4-way, crossover study was conducted at the Department of Nutrition, Exercise and Sport, University of Copenhagen, from September 2014 to March 2015. The study was carried out in accordance with the Declaration of Helsinki and all subjects gave their written informed consent for inclusion before they participated in the study. The protocol was approved by the Municipal Ethical Committee of the Capital Region, Denmark (journal number H-1-2014-038) and the study was registered at clinicaltrials.gov (NCT02770833).

\subsection{Experimental Protocol}

On the test days, which were conducted with a separation of minimum one week, the participants arrived in a fasting state at 7:30 AM. The participants were then required to try to void urine, and body weight was measured (Lindeltronic 8000 , Samhall lavi AB, Kristianstad, Sweden). Hereafter, participants laid down in a supine position and the non-dominant hand was placed in a heat box. Blood pressure and temperature were measured after $15 \mathrm{~min}$ of rest and an intravenous catheter was inserted into the back of the heated hand. At 8:15 AM, appetite and gastrointestinal feelings were registered and a fasting blood sample was drawn [25]. Then, resting metabolic rate (RMR) was measured with a ventilated hood system (Jaeger Oxycon PRO; Viasys Healthcare GmbH, Höchberg, Germany). At 8:55 AM, the participants received one of the four test meals. They were instructed to eat the test meal at a constant pace and to distribute the consumption over a period of $15 \mathrm{~min}$. Hereafter, appetite sensations and general palatability of the test meal were assessed with visual analog scales (VAS). The following three hours, respiratory gas exchange was measured six times for $25 \mathrm{~min}$ 
with 5-min breaks with a ventilated hood system. Appetite sensations were assessed with VAS every half hour after the test meal, and blood samples were drawn every 20 min until 12:30 PM, where gastrointestinal experiences were also assessed. Then, the participants were required to empty their bladder, and the urine was collected for nitrogen analysis. The participants were, afterwards, served an ad libitum buffet-style lunch. A table of the measurements and time points can be found in Table S1.

\subsection{Subjects}

Healthy overweight men and women were recruited from the Copenhagen area through advertisements in newspapers, the web page www.fors $\backslash \mathrm{T} 1 \backslash$ ogsperson.dk, and the website of the Department of Nutrition Exercise and Sports. To be included in the study, participants had to have a body mass index (BMI) between 25.0 and $30.0 \mathrm{~kg} / \mathrm{m}^{2}$. This was chosen as overweight individuals often wish to lose weight. Furthermore, the participants had to be non-smoking, between 18 and 50 years of age, with a fasting blood glucose level below $5.9 \mathrm{mmol} / \mathrm{L}$. Exclusion criteria included: chronic diseases, use of prescription medication that has the potential to affect body weight or glucose metabolism, psychoactive medication, epileptic medication or weight loss medications, self-reported eating disorders or irregular eating schedule (e.g., skipping breakfast), food allergies, substance abuse, vigorous physical activity of more than $10 \mathrm{~h} /$ week, alcohol intake above the recommendations from the Danish Health Authority (7 or 14 units per week for women and men, respectively), daily caffeine intake above $300 \mathrm{mg}$, night- or shift work, blood donation less than 1 month before study commencement and during the study period, and simultaneous participation in other clinical studies. Pregnant or breastfeeding women or women who intended to become pregnant during the study period, menopausal women, and women with an irregular menstrual cycle were furthermore excluded.

\subsection{Standardization}

The participants were required and instructed to eat a standardized $3500 \mathrm{~kJ}$ dinner, provided as frozen product, between 7:00 PM and 8:00 PM the evening before the test days, the dinner consisted of a chicken paprika dish served with rice and orange juice: (16.6 E\% protein, 50.1 E\% carbohydrate and $33.3 \mathrm{E} \%$ fat, $4.9 \mathrm{~g}$ fiber/meal). From 8:00 PM the participants were required to fast. However, consumption of $500 \mathrm{~mL}$ water was allowed during fasting, though maximum $250 \mathrm{~mL}$ in the morning of the test day. The participants were not allowed to do vigorous physical activity, take any medicine, or to drink alcohol $48 \mathrm{~h}$ before the test days. On the test days, participants arrived by transport requiring a minimum of physical activity (i.e., by car, bus or train). They were required to use the same means of transportation on all four test days.

\subsection{Test Meals}

The test meals were: patties of salmon served with mashed potatoes (SM), patties of salmon served with wholegrain pasta (SP), patties of veal served with mashed potatoes (VM), and patties of veal served with wholegrain pasta (VP). Additionally, the test meals were served with tomato sauce and water. Based on data from the Danish dietary software program Dankost $3000^{\circledR}$ (Dansk Catering Center, Copenhagen, Denmark), the test meals were iso-caloric $\sim 2011 \mathrm{~kJ} / \mathrm{meal}$ and had similar macronutrient distribution (approximately $25.5 \mathrm{E} \%$ protein, $40.5 \mathrm{E} \%$ carbohydrate, $34.0 \mathrm{E} \%$ fat), energy density, and fiber content $(\sim 4.9 \mathrm{~g})$, see Table 1 . The wholegrain pasta was characterized as low GI and the mashed potatoes as high GI [26]. 
Table 1. Recipes and nutritional content of the four test meals.

\begin{tabular}{lcccc}
\hline & SM & SP & VM & VP \\
\hline Salmon filet, g & 108.8 & 108.8 & - & - \\
Wholegrain pasta, g & - & 45.2 & - & 44 \\
Veal, g & - & - & 108.8 & 108.8 \\
Mashed Potato Powder, g & 48.0 & - & 46.8 & - \\
Tomato puree concentrate, g & 17.6 & 17.6 & 17.6 & 17.6 \\
Onion, g & 22.4 & 22.4 & 22.4 & 22.4 \\
Table salt, g & 2.4 & 2.4 & 2.4 & 2.4 \\
Water, g & 28.8 & 28.8 & 28.8 & 28.8 \\
Whole egg, g & 9.6 & 9.6 & 9.6 & 9.6 \\
Onion, g & 9.6 & 9.6 & 9.6 & 9.6 \\
Cream 38\% fat, g & 11.2 & 11.2 & 11.2 & 11.2 \\
Breadcrumbs, g & 9.6 & 9.6 & 9.6 & 9.6 \\
Water with meal, g & 216 & 219 & 217 & 220 \\
\hline Energy kJ & 2012 & 2011 & 2012 & 2010 \\
Total weight (g) & 484 & 484 & 484 & 484 \\
Energy density (kJ/g) & 4.16 & 4.15 & 4.16 & 4.15 \\
\hline Protein \%E & 25.1 & 25.7 & 25.1 & 25.7 \\
Protein, g & 29.8 & 30.4 & 29.8 & 30.3 \\
Fat \%E & 34.3 & 33.3 & 35.0 & 34.0 \\
Fat, g & 18.6 & 18.1 & 19.0 & 18.5 \\
Carbohydrate \%E & 40.6 & 41.1 & 39.8 & 40.3 \\
Carbohydrate, g & 45.8 & 46.2 & 44.9 & 45.3 \\
Fiber, g & 4.8 & 5.0 & 4.7 & 4.9 \\
\hline Saturated fat, g & 6.6 & 5.7 & 9.1 & 8.2 \\
Mono unsaturated fat, g & 5.4 & 5.4 & 7.3 & 7.3 \\
Poly unsaturated fat, g & 4.4 & 4.4 & 0.9 & 0.9 \\
n-3 fatty acids & 3.6 & 3.6 & 0.2 & 0.2 \\
n-6 fatty acids & 0.8 & 0.8 & 0.7 & 40 \\
\hline GI & 85 & 40 & 85 & 18 \\
GL & 35 & 16 & 38 & \\
\hline M & & & & \\
\hline
\end{tabular}

SM, salmon and mashed potatoes; SP, salmon and pasta; VM, veal and mashed potatoes; VP, veal and pasta. $\mathrm{E} \%$, energy percentage; GI, glycemic index; GL, glycemic load.

The concentrations of individual amino acids in the diets were analyzed on the ACQUITY UPLC $^{\circledR}$ System (Waters, Milford, MA, USA), except for tryptophan. The methods have been described previously [27]. Based on the analyses of individual amino acids in the test meals, the SM, SP, VM, and VP meals contained a total of $25.6 \mathrm{~g}, 25.4 \mathrm{~g}, 29.5 \mathrm{~g}$, and $30.1 \mathrm{~g}$ amino acids, respectively, see Table 2.

Table 2. Amino acids composition of the four test meals ${ }^{1}$.

\begin{tabular}{lllll}
\hline & SM & SP & VM & VP \\
\hline Histidine & \multicolumn{2}{c}{$\mathrm{g} / \mathrm{meal}$} \\
Taurine & 0.68 & 0.68 & 0.90 & 0.89 \\
Serine & 0.03 & 0.04 & 0.07 & 0.07 \\
Arginine & 1.11 & 1.14 & 1.22 & 1.28 \\
Glycine & 1.52 & 1.48 & 1.81 & 1.84 \\
Aspartic acid & 1.21 & 1.18 & 1.53 & 1.64 \\
Glutamic acid & 3.05 & 2.41 & 3.25 & 2.72 \\
Threonine & 4.10 & 4.81 & 5.10 & 5.83 \\
Alanine & 1.20 & 1.13 & 1.28 & 1.25 \\
Lysine & 1.46 & 1.41 & 1.67 & 1.69 \\
Tyrosine & 2.28 & 2.02 & 2.51 & 2.30 \\
Methionine & 0.94 & 0.89 & 0.97 & 0.96 \\
\hline
\end{tabular}


Table 2. Cont.

\begin{tabular}{lcccc}
\hline & SM & SP & VM & VP \\
\hline \multicolumn{5}{c}{ V/meal } \\
\hline Valine & 1.44 & 1.37 & 1.50 & 1.47 \\
Isoleucine & 1.15 & 1.10 & 1.26 & 1.24 \\
Leucine & 2.05 & 2.04 & 2.33 & 2.37 \\
Phenylalanine & 1.19 & 1.23 & 1.29 & 1.34 \\
Proline & 1.07 & 1.36 & 1.43 & 1.75 \\
Hydroxyproline & 0.06 & 0.05 & 0.26 & 0.29 \\
Tryptophan & 0.31 & 0.37 & 0.37 & 0.42 \\
\hline Total & 25.59 & 25.39 & 29.46 & 30.08 \\
\hline
\end{tabular}

${ }^{1}$ Asparagine and glutamine are not included as they are hydrolyzed to aspartic acid and glutamic acid, respectively. The concentration of cysteine was not assessed. SM, salmon and mashed potatoes; SP, salmon and pasta; VM, veal and mashed potatoes; VP, veal and pasta.

\subsection{Energy Expenditure and Substrate Oxidation}

Energy expenditure (EE) and substrate oxidation were measured with a ventilated hood system (Jaeger Oxycon PRO; Viasys Healthcare GmbH, Höchberg, Germany). The precision of the system was validated by a weekly alcohol-burning test. EE and oxidation of carbohydrate, fat, and protein were calculated from the gas exchange and the urinary nitrogen measurements using constants of Elia and Livesey [28]. DIT was calculated as area under the EE curve above fasting (RMR) level ( $\mathrm{kJ} / \mathrm{min}$ * $\mathrm{min}$ ), the last $20 \mathrm{~min}$ of the $25 \mathrm{~min}$ measurements of EE were used for the calculation.

\subsection{Visual Analog Scales}

Appetite sensations and evaluations of the meals were assessed by VAS with a length of $100 \mathrm{~mm}$ [25]. At each end of the line, the most extreme rating was expressed [25]. Participants answered questions regarding satiety, hunger, fullness, prospective food consumption (PFC), and desire to eat something salty, sweet, meat/fish, or fat-rich. The test meals and the ad libitum buffet-style lunch were rated with regard to visual appearance, odor, palatability, off taste and general appearance. Zero corresponded to the most positive rating and 100 to the most negative rating in the evaluation of the meals. The participants completed eight yes/no questions regarding gastrointestinal symptoms (bloating, diarrhea, rumbling, throat burn, flatulence, nausea, acid reflux, and stomach pain). The questionnaires on gastrointestinal symptoms were filled in before the test meal was ingested, and at 110 and $200 \mathrm{~min}$ after ingestion of the test meal. If the participants answered yes to a gastrointestinal symptom, they had to register the intensity on a VAS of $100 \mathrm{~mm}$ in length. The VAS questionnaires were answered on an electronic tablet-based VAS (eVAS). The eVAS system was set up on an HP Slate 2 tablet using Acqui version 1 (xyzt, Copenhagen, Denmark). Appetite ratings with eVAS has previously been validated and found comparable to the pen-and-paper method [12].

\subsection{Ad Libitum Buffet Style Lunch}

The ad libitum buffet style lunch consisted of a variety of cold and hot foods, and represented a typical Danish lunch. The participants were instructed to eat at a constant pace and to stop eating when they felt pleasantly satiated. All foods were weighted to the nearest gram, by an experienced food technician, before and after the meal.

\subsection{Biochemical Analyses}

All blood samples were drawn by the heated-hand box method [29]. A catheter was inserted to a vein on the back on the hand, and the hand was then placed in a cavity where heated air circulated to warm the hand to $50{ }^{\circ} \mathrm{C}$. 
Blood for analyses of plasma lactate and glucose was drawn into tubes prepared with sodium fluoride-oxalate. Blood collected for analyses of serum C-peptide and insulin was drawn into serum clot activator tubes. Blood for analysis of plasma triglycerides (TAG) was drawn into tubes prepared with EDTA while blood for analysis of plasma ghrelin levels was drawn into EDTA-prepared tubes containing aprotinin. Immediately after the blood samples were drawn, blood for analyses of glucose, lactate, TAG, and ghrelin was centrifuged $\left(2500 \times \mathrm{g}\right.$ for $10 \mathrm{~min}$ at $\left.4{ }^{\circ} \mathrm{C}\right)$. Blood for analyses of insulin and C-peptide was allowed to coagulate for $20 \mathrm{~min}$ before centrifugation. Afterwards, all samples were frozen and stored at $-80^{\circ} \mathrm{C}$ until they were analyzed. Plasma lactate, glucose and TAG were analyzed on an ABX Pentra 400, HORIBA, CA, USA (plasma glucose: intra CV \%: 1.4, inter CV \%: 2.5; plasma lactate: intra CV \%: 0.2, inter CV \%: 0.9, plasma TAG: intra CV \%: 1.5, inter CV \% 2.0). Serum insulin and C-peptide were analyzed on an Immulite 1000, Siemens, Erlangen, Germany (serum insulin: intra CV \%: 4.2, inter CV \%: 4.2; serum C-peptide: intra CV \%: 2.5, inter CV \%: 1.8). Total plasma ghrelin was analyzed with an enzyme-linked immunosorbent assay produced by EMD Millipore, MA, USA (intra CV \%: 3.8, inter CV \%: 8.9).

To calculate protein oxidation, all urine produced by the participants during the measurements of EE on each test day was collected and weighed, and a $10 \mathrm{~mL}$ sample was used for the analysis of nitrogen. Urinary nitrogen was measured on an Elementar VarioMax CN analyzer, Elementar, Langenselbold, Germany (intra CV \%: $2.0 \%$, inter CV\%: 3.4 ).

Plasma amino acids were analyzed in a subsample of five subjects (all sampling points), which were randomly chosen among the subjects. The small subsample was due to financial constraints. Blood samples for analyses of plasma amino acids were drawn into heparin-prepared tubes, and plasma amino acids were quantified by nuclear magnetic resonance (NMR) spectroscopy. Prior to NMR spectroscopy, the $300 \mu \mathrm{L}$ of plasma sample was filtered using Amicon Ultra $0.5 \mathrm{~mL} 3 \mathrm{kDa}$ (Millipore, MA, USA) spin filters at $14,000 \mathrm{~g}$ for $1 \mathrm{~h}$ at $4{ }^{\circ} \mathrm{C} .200 \mu \mathrm{L}$ of filtered sample was added $70 \mu \mathrm{L} \mathrm{D} \mathrm{D}_{2} \mathrm{O}$ and $330 \mu \mathrm{L}$ phosphate buffer also containing 3-(Trimethylsilyl)-1-propanesulfonic acid- $\mathrm{d}_{6}$ sodium salt (DSS; Sigma-Aldrich, MO, USA) and formate (Sigma-Aldrich, MO, USA). Final concentration of buffer was $50 \mathrm{mM} \mathrm{Na}_{2} \mathrm{HPO}_{4}, 0.25 \mathrm{mM}$ DSS, and $117 \mu \mathrm{M}$ formate. ${ }^{1} \mathrm{H}$ NMR spectroscopy was performed at $298 \mathrm{~K}$ on a Bruker Avance III 600 spectrometer, operating at a ${ }^{1} \mathrm{H}$ frequency of $600.13 \mathrm{MHz}$, and equipped with a 5-mm ${ }^{1} \mathrm{H}$ TXI probe (Bruker BioSpin, MA, USA). The sample sequence was randomized prior to acquisition and standard one-dimensional spectra were acquired using noesyprld pulse sequence with water presaturation during relaxation delay and mixing time. Relaxation delay was $5 \mathrm{~s}$, mixing time was $0.1 \mathrm{~s}$ and a total of 64 scans were collected into 32,768 data points spanning a spectral width of $12.02 \mathrm{ppm}$. All ${ }^{1} \mathrm{H}$ NMR spectra were referenced to the DSS signal at $0 \mathrm{ppm}$. The data was multiplied by a $0.3 \mathrm{~Hz}$ line-broadening function prior to Fourier transformation. The proton NMR spectra were phase- and baseline corrected manually using Topspin 3.2 (Bruker BioSpin, MA, USA). Amino acids were quantified using Chenomx NMR Suite 8.1.2 (Chenomx Incorporated, Edmonton, Canada).

\subsection{Blinding and Randomization}

The participants were randomly allocated to a combination of the four test meals. The randomization, which was conducted by the study coordinator, was stratified between gender, i.e., two separate randomization lists of the meal sequences were generated using an online randomization program [30]: one to allocate men and one to allocate women. It was not possible to blind the study, as the smell and appearance of the four test meals could not be concealed.

\subsection{Sample Size}

The sample size calculation was based on results from a previous study [31]. Thus, 20 subjects would give a statistical power of $90 \%$ to detect a $35 \mathrm{~kJ}$ difference in DIT with a within-subject SD of $32 \mathrm{~kJ}$ at a 2 -sided $5 \%$ significance level. 


\subsection{Statistical Analysis}

Baseline data are presented as mean \pm standard derivation (SD). Models for summary measures (DIT, iAOC [incremental area over the curve], iAUC [incremental area under the curve], ad libitum EI, time to peak, and the evaluation of the test meals) included meal as a main effect and subject as a random effect, and were adjusted for sex, age, BMI, and visit number. In case a significant meal effect was found, model-based pairwise comparisons, adjusted for multiple testing, were used to identify differences between test meals. DIT, iAUC, and iAOC were calculated using the trapezoidal rule. Time to peak was determined as the time point where the maximum response was observed. Models to investigate differences in satiety, hunger, fullness, or PFC, both as summary measures and repeated measures, were additionally adjusted for palatability of the test meals. Repeated measurements were analyzed with linear mixed models. The models included a meal-time interaction and overall subject and within-visit subject differences were included as random effects. The models were adjusted for age, sex, visit number, BMI, and fasting value on the test day. Serial correlation between repeated measurements for the same subject within each visit was modeled, assuming a spatial Gaussian correlation structure (exponentially decreasing correlation over time). Time points with differences between meals were identified with model-based pairwise comparisons, adjusted for multiple testing. Multiplicity adjustment of $P$ values was based on the single-step method [32].

For all models, assumption of normality and homogeneity of variance were evaluated graphically using residual plots and normal probability plots. Fisher's exact test was used to analyze if there were differences in the occurrence of gastrointestinal side effects.

Results are presented as mean \pm standard error (SE) or mean differences between meals $\pm \mathrm{SE}$ unless otherwise stated. Graphs are based on unweighted averages. $P$ values $<0.05$ were considered significant. All statistical analyses were conducted in $\mathrm{R}$ version 3.1.2 ( $\mathrm{R}$ Core Team, 2016, Vienna, Austria).

\section{Results}

\subsection{Subjects}

Forty subjects attended a screening visit, 15 of these did not meet the inclusion criteria. Thus, 25 subjects, 12 men and 13 women, were randomized to the study (Table 3).

Table 3. Baseline characteristics of the 25 overweight men and women ${ }^{1}$.

\begin{tabular}{ll}
\hline Characteristics & Values \\
\hline Age, $\mathrm{y}$ & $28.8 \pm 7.6$ \\
Weight, $\mathrm{kg}$ & $83.3 \pm 9.2$ \\
Height, $\mathrm{m}$ & $174 \pm 7$ \\
BMI, $\mathrm{kg} / \mathrm{m}^{2}$ & $27.5 \pm 1.5$ \\
Systolic blood pressure, $\mathrm{mmHg}$ & $119 \pm 9$ \\
Diastolic blood pressure, $\mathrm{mmHg}$ & $73 \pm 6$ \\
Fasting glucose, mmol/L & $5.1 \pm 0.4$ \\
\hline
\end{tabular}

${ }^{1}$ Data are presented as mean $\pm \mathrm{SD}$.

Five subjects dropped out after the first test day. Twenty subjects completed all four test days, see (Figure 1). 


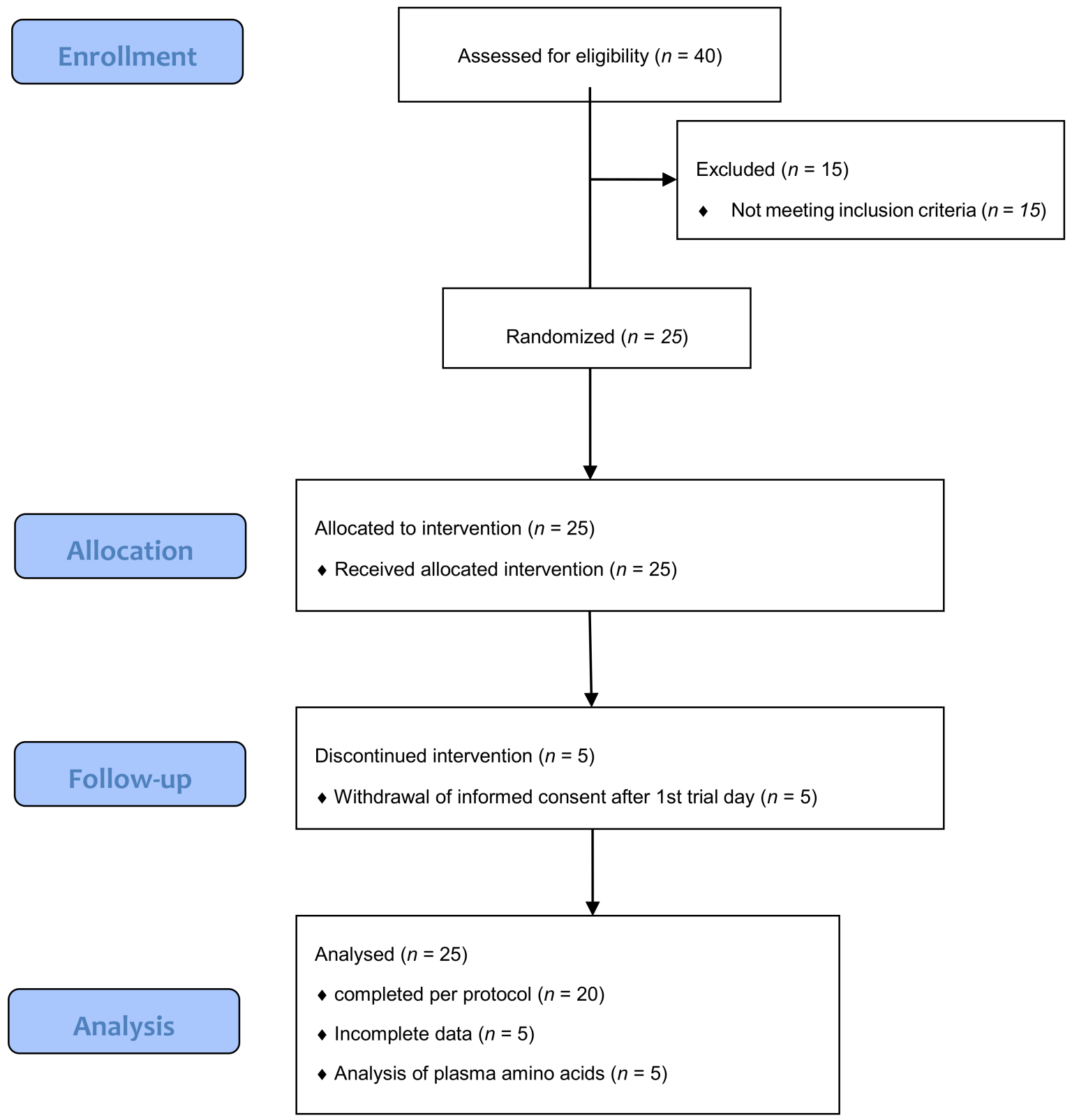

Figure 1. Participant flowchart.

\subsection{DIT and Substrate Oxidation}

A main effect of meal was found for DIT ( $p=0.005$ ), see Figure $2 \mathrm{~b}$. DIT was $40 \%$ higher after the SM meal compared to the SP meal $(p=0.002)$. No interaction between meal and time was found for the postprandial increase in EE $(p=0.33)$. However, a meal effect was found $(p=0.004)$. The SM meal resulted in an increased postprandial EE compared to the SP meal (mean difference between the SM and the SP meal: $0.24 \pm 0.07 \mathrm{~kJ} / \mathrm{min}, p=0.001$ ) and the VP meal (mean difference between the SM meal and the VP meal: $0.18 \pm 0.07 \mathrm{~kJ} / \mathrm{min}, p=0.04$ ), see Figure $2 \mathrm{a}$.

No meal-time interaction was found for postprandial fat oxidation or carbohydrate oxidation $(p=0.47$ and $p=0.76$, respectively). However, a main effect of meal was found for both parameters $(p<0.001$ and $p=0.002$, respectively). Carbohydrate oxidation was increased after the SM meal compared to the SP meal $(p=0.03)$ and after the VM meal compared to the SP meal $(p=0.004)$ and the VP meal $(p=0.049)$. When analyzed as iAUC a higher carbohydrate oxidation was found after the SM and VM meals compared to the SP meal (all $p<0.05$ ), see Figures $2 \mathrm{c}$ and $2 \mathrm{~d}$. 


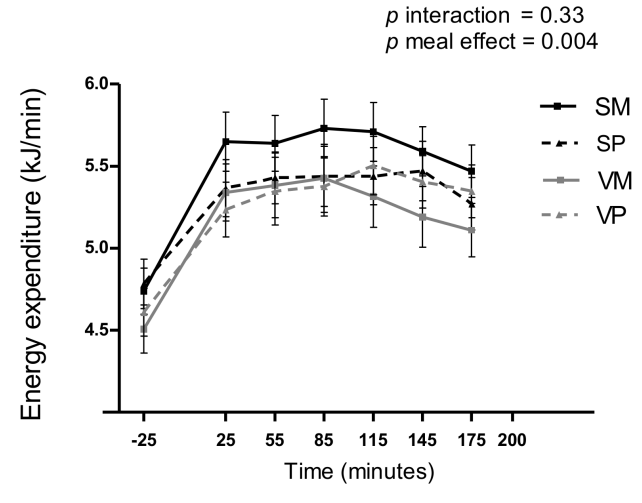

(a)

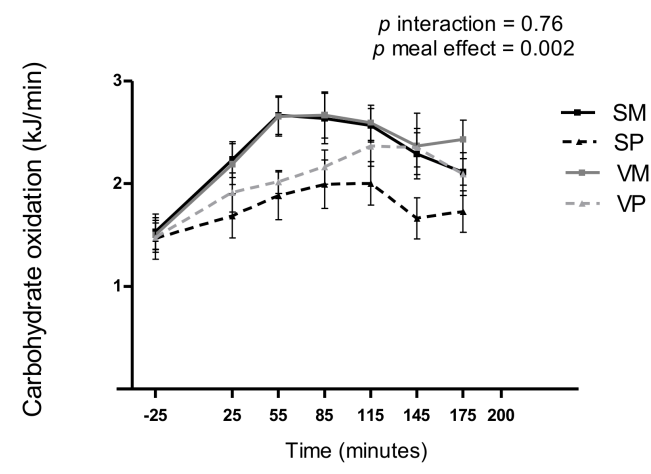

(c)

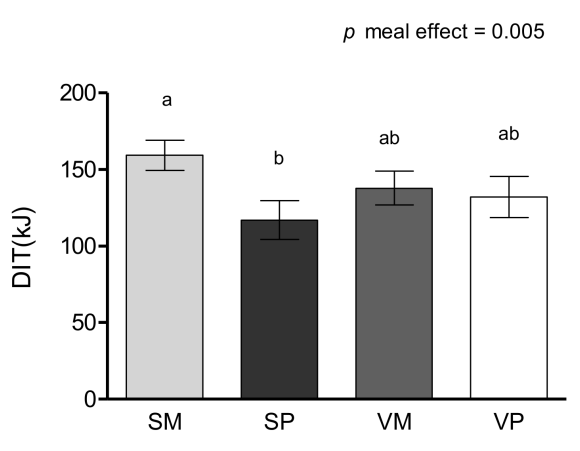

(b)

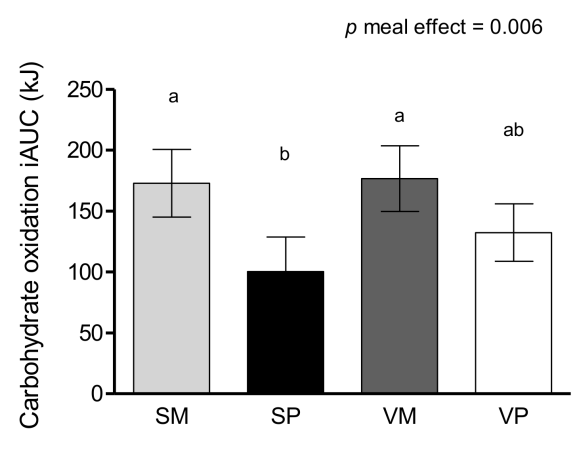

(d)

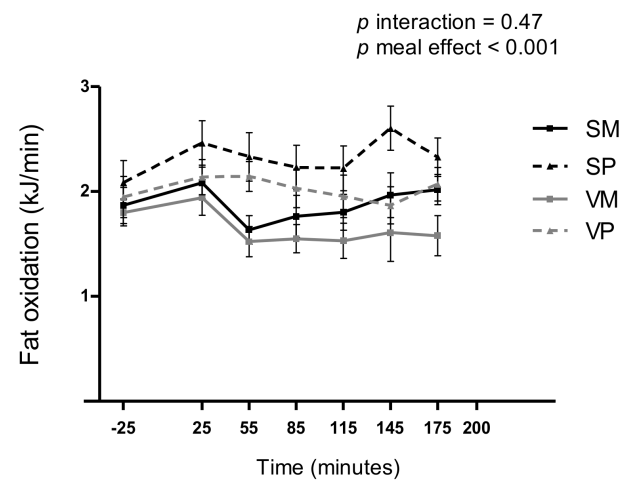

(e)

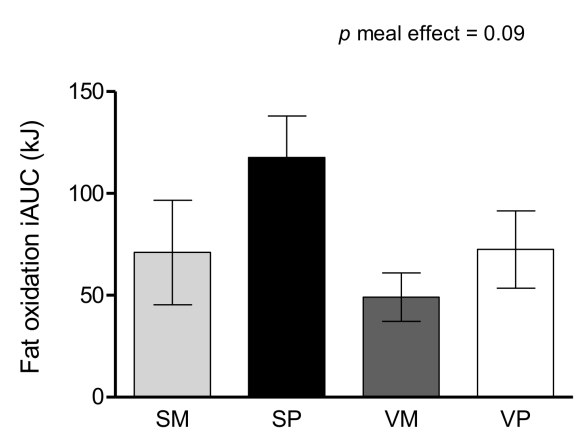

(f)

Figure 2. Mean unadjusted measures of EE (a), DIT (b), carbohydrate oxidation (c), carbohydrate oxidation iAUC (d), fat oxidation (e), and fat oxidation iAUC (f) after intake of four different test meals: SM, SP, VM, and VP. Data are presented as means \pm standard error of mean (SEM), $n=25$. Measurements over time were analyzed as repeated measures including a meal-time interaction using linear mixed models, post hoc comparisons were single-step adjusted. iAUC was analyzed using a linear mixed model including meal as a fixed effect, means not sharing a common letter differ. DIT, diet-induced thermogenesis; EE, energy expenditure; iAUC, incremental area under the curve; SM, salmon and mashed potatoes; SP, salmon and wholegrain pasta; VM, veal and mashed potatoes; VP, veal and wholegrain pasta. 
Fat oxidation was higher after the SP meal than after SM, VM, and VP meals $(p=0.001, p<0.001$, and $p=0.038$, respectively). Additionally, fat oxidation was higher after the SM meal compared to the VM meal ( $p=0.036)$ and after the VP meal compared with the VM meal $(p=0.001)$. When fat oxidation was analyzed as iAUC no differences were found between meals, see Figures $2 \mathrm{e}$ and $2 \mathrm{f}$. There were no differences in protein oxidation between the test meals $(p=0.52)$.

\subsection{Appetite Sensations}

There were no interactions between meal and time in any of the appetite parameters (satiety, hunger, fullness, or PFC) (all $p>0.05)$. A meal effect was found for PFC ( $p=0.012)$, see Figure 3a. Here, the VP meal resulted in a higher PFC compared to the SM meal $(8.7 \pm 2.9 \mathrm{~mm}, p=0.022)$. There were no differences in satiety, hunger, or fullness. The results were similar when the appetite parameters were adjusted for palatability of the test meals or overall appearance. There were no differences between test meals when satiety, fullness, hunger, or PFC were analyzed as iAUC or iAOC (all $p>0.05$ ).

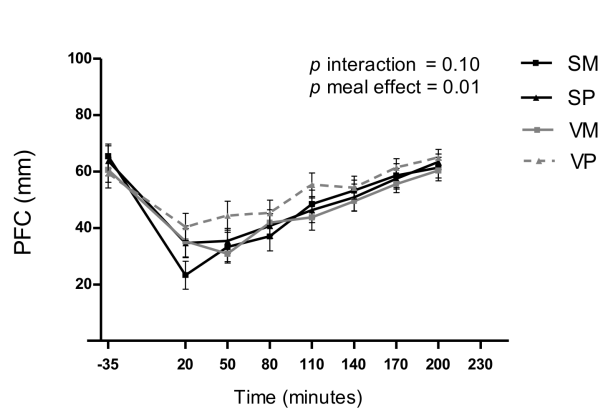

(a)

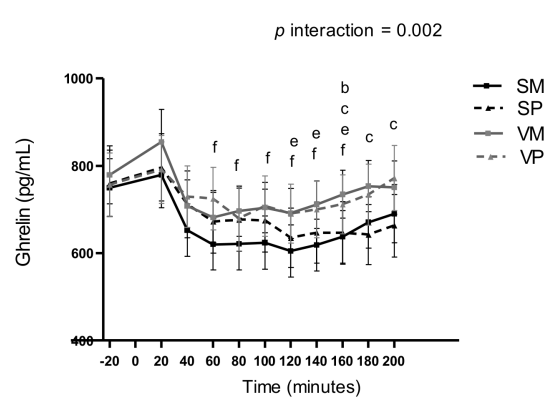

(c)

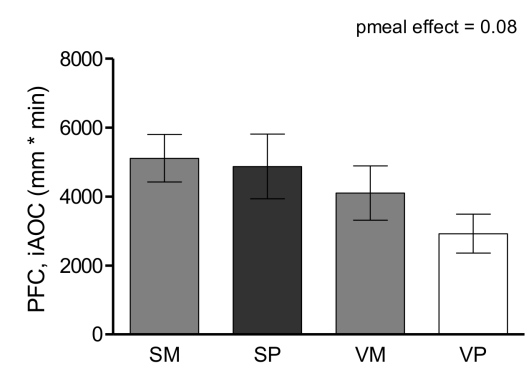

(b)

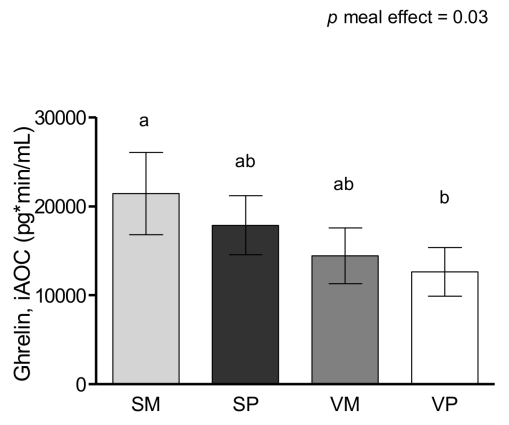

(d)

Figure 3. Mean unadjusted measures of PFC (a), iAOC PFC (b), plasma ghrelin (c) and iAOC ghrelin (d) after intake of four different test meals: SM, SP, VM, and VP. Data are presented as means \pm SEM, $n=25$. Measurements over time were analyzed as repeated measures including a meal-time interaction using linear mixed models. ${ }^{\mathrm{b}}$ difference between the VM and SM meals $(P<0.05),{ }^{\mathrm{c}}$ difference between the VM and SP meals $(P<0.05)$, e difference between the SP and VP meals $(P<0.05)$, ${ }^{\mathrm{f}}$ difference between the SM and VP meals $(P<0.05)$. iAOC was analyzed using linear mixed models including meal as a fixed effect, means not sharing a common letter differ. PFC, prospective food consumption; iAOC, incremental area over the curve; iAUC, incremental area under the curve; SM, salmon and mashed potatoes; SP, salmon and wholegrain pasta; VM, veal and mashed potatoes; VP, veal and wholegrain pasta.

No interactions between meal and time or meal effects were observed for the desire to eat meat or fish, or for the specific taste of sweet or salt. However, a meal effect was found for the desire for something fat rich, which was lower after the SM meal compared to the SP meal (12.5 $\pm 3.8 \mathrm{~mm}$, $p=0.005$ ). 


\subsection{Ad Libitum Energy Intake}

There were no differences between the four test meals in ad libitum EI or the macronutrient distribution of the ingested food at the buffet style lunch (all $p>0.05)$ (Table 4 ).

Table 4. Ad libitum energy intake after the four different test meals ${ }^{1}$.

\begin{tabular}{ccccc}
\hline & SM & SP & VM & VP \\
\hline Total energy intake, kJ & $4911 \pm 559$ & $4975 \pm 556$ & $5059 \pm 545$ & $5059 \pm 535$ \\
Protein, kJ & $735 \pm 110$ & $812 \pm 109$ & $808 \pm 107$ & $808 \pm 104$ \\
Carbohydrates, kJ & $2301 \pm 222$ & $2275 \pm 220$ & $2320 \pm 214$ & $2184 \pm 207$ \\
Fat, kJ & $1863 \pm 286$ & $1881 \pm 284$ & $1919 \pm 278$ & $2061 \pm 272$ \\
\hline
\end{tabular}

${ }^{1}$ Data are presented as means \pm SE. Data was analyzed using linear mixed models with meal as fixed effect, adjusted for sex, age, BMI, and visit number. There were no differences between test meals in total energy intake or macronutrient distribution. SM, salmon and mashed potatoes; SP, salmon and wholegrain pasta; VM, veal and mashed potatoes; VP, veal and wholegrain pasta.

\subsection{Ghrelin}

There was a significant meal-time interaction for plasma ghrelin $(p=0.002)$. Pairwise comparisons showed that plasma ghrelin levels were generally more suppressed after the salmon meals compared to the veal meals, see Figure 3c. When ghrelin was analyzed as iAOC a meal effect was found $(p=0.03)$, iAOC was higher after the SM meal compared with the VP meal $(p=0.02)$.

\subsection{Glucose and Insulin}

A meal-time interaction was found for postprandial glucose concentrations $(p<0.001)$. Thus, the glucose peak $40 \mathrm{~min}$ after the test meal was significantly higher after the meals with veal compared to the meals with salmon in combination with the same type of carbohydrate (mean difference between the VM and the SM meal: $0.67 \pm 0.16 \mathrm{mmol} / \mathrm{L} p<0.001$, mean difference between the VP and the SP meal: $0.44 \pm 0.16 p=0.033$ ). The VM meal resulted in the highest glucose peak, while the glucose peak was lowest after the SP meal (all $p$ for comparisons between meals $<0.05$ ). The SM meal and the VP meal induced a similar glucose peak $(p>0.999)$. When glucose concentrations were analyzed as iAUC no differences were found between test meals (Figures $4 \mathrm{a}$ and $4 \mathrm{~b}$ ).

A meal-time interaction was observed for insulin. The meals with mashed potatoes induced higher insulin responses at 20 and 40 min compared with the meals with pasta (all $p<0.05$ ). When insulin was analyzed as iAUC a meal effect was found $(p=0.0002)$, the meals with mashed potatoes induced a higher insulin response compared with the meals with pasta (all $p<0.05$ ), see Figures $4 \mathrm{c}$ and $4 \mathrm{~d}$.

A meal-time interaction was also found for plasma lactate and serum C-peptide ( $p=0.01$ and $p=0.003$, respectively). Differences between the test meals again depended on the type of carbohydrate (Figure S1). 


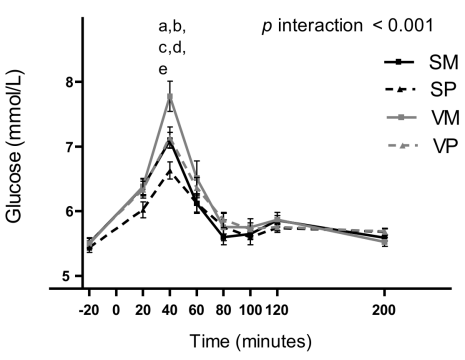

(a)

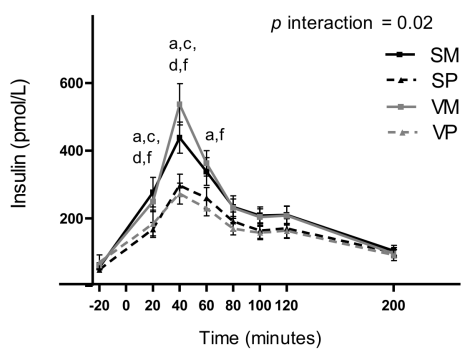

(c)

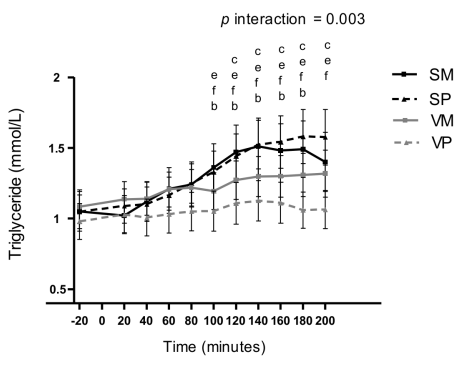

(e)

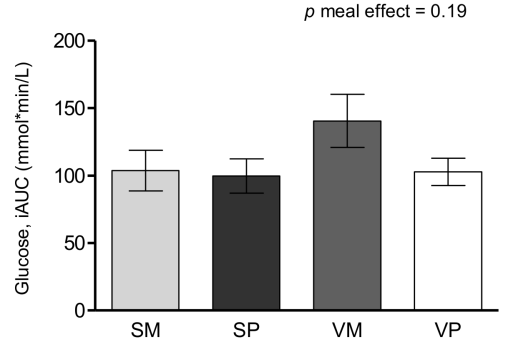

(b)

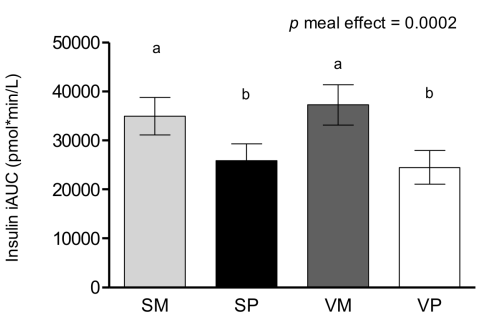

(d)

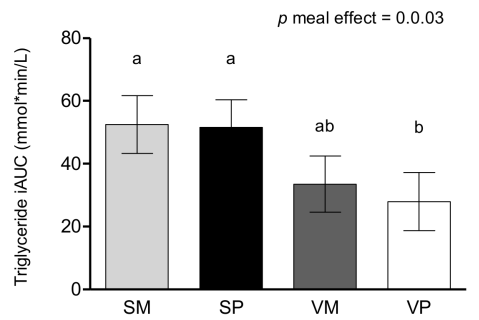

(f)

Figure 4. Mean unadjusted concentrations of plasma glucose (a), plasma glucose iAUC (b), serum insulin (c), serum insulin iAUC (d), plasma triglyceride (e), and plasma triglyceride iAUC (f) after intake of four different test meals: SM, SP, VM, and VP. Data are presented as means \pm SEM, $n=25$. Measurements over time were analyzed as repeated measures including a meal-time interaction using linear mixed models, post hoc comparisons were single-step adjusted. Meal-time interactions were found for glucose, insulin and triglyceride. ${ }^{a}$ difference between the VM and VP meals $(p<0.05)$, $\mathrm{b}$ difference between the VM and SM meals $(p<0.05),{ }^{\mathrm{c}}$ difference between the VM and SP meals $(p<0.05),{ }^{d}$ difference between the SM and SP meals $(p<0.05),{ }^{\mathrm{e}}$ difference between the SP and VP meals $(p<0.05),{ }^{\mathrm{f}}$ difference between the SM and VP meals $(p<0.05)$. iAUC was analyzed using linear mixed models including meal as a fixed effect, means not sharing a common letter differ. iAUC, incremental area under the curve; SM, salmon and mashed potatoes; SP, salmon and pasta; VM, veal and mashed potatoes; VP, veal and pasta.

\subsection{Triglycerides}

A meal-time interaction was found for TAG $(p=0.003)$. From 100 to $200 \mathrm{~min}$, plasma TAG concentrations were generally higher after the salmon meals compared to the veal meals, see Figure 4e. When TAG was analyzes as iAUC a meal effect was found $(p=0.003)$, showing that the SM meal and the SP meal induced higher responses compared with the VP meal ( $p=0.01$ and $p=0.01$, respectively). 


\subsection{Plasma Amino Acids}

Postprandial plasma responses of leucine and total amino acids are shown in Figure 5. A meal-time interaction was found for the postprandial increase in plasma concentrations of total amino acids, leucine, tyrosine, asparagine, glycine, histidine, isoleucine, lysine, methionine, phenylalanine, threonine and valine (all $p<0.05)$, whereas meal effects were found for alanine and arginine (Table S2). A meal effect was found for time to peak of total plasma amino acid concentration $(p=0.006)$. Time to peak was $82 \pm 37$ min after the SM meal, $128 \pm 33$ min after the SP meal, $93 \pm 32$ min after the VM meal, and $132 \pm 46 \mathrm{~min}$ after the VP meal. The total amino acid concentration peaked earlier after the SM meal compared with the SP and VP meals ( $p=0.008$ and $p=0.03$, respectively), no other differences were observed in time to peak (all $p>0.05)$, see Figure $5 b$.

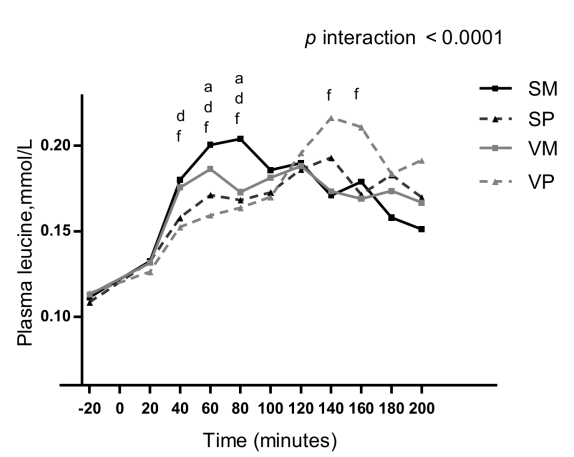

(a)

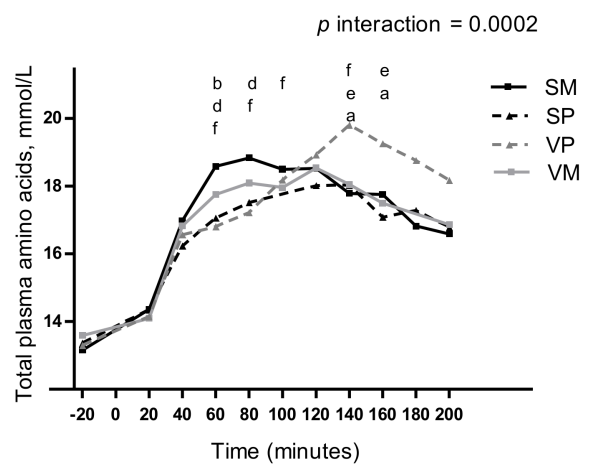

(b)

Figure 5. Mean unadjusted changes in plasma leucine (a) and total plasma amino acids (b), after intake of four different test meals: SM, SP, VM, and VP. Data are presented as means \pm SEM, $n=5$. Data were analyzed as repeated measures including a meal-time interaction using linear mixed models. Post hoc comparisons were single-step adjusted. ${ }^{a}$ difference between the VM and VP meals $(p<0.05)$, $\mathrm{b}$ difference between the VM and SM meals $(p<0.05)$, d difference between the SM and SP meals $(p<0.05),{ }^{\text {e }}$ difference between the SP and VP meals $(p<0.05),{ }^{\mathrm{f}}$ difference between the SM and VP meals $(p<0.05)$. SM, salmon and mashed potatoes; SP, salmon and pasta; VM, veal and mashed potatoes; VP, veal and pasta.

\subsection{Evaluations of the Test Meals}

The SM meal resulted in a lower ratings of visual appearance and general appearance compared to the VP meal ( $p=0.004$ and $p=0.04$, respectively). Moreover, the SM meal resulted in a lower rating of visual appearance compared to the VM meal $(p=0.03)$, (Table 5). There were no differences in the evaluation of palatability, off taste, or smell between the four test meals (all $p>0.05$ ).

Table 5. Palatability evaluations of the four test meals ${ }^{1}$.

\begin{tabular}{ccccc}
\hline & SM & SP & VM & VP \\
\hline General appearance $(\mathrm{mm})$ & $63.6 \pm 6.4^{\mathrm{a}}$ & $59.8 \pm 6.3$ & $53.5 \pm 6.0$ & $50.5 \pm 5.5^{\mathrm{a}}$ \\
Look (mm) & $78.1 \pm 6.8^{\mathrm{ab}}$ & $72.4 \pm 6.7$ & $63.9 \pm 6.4^{\mathrm{b}}$ & $60.5 \pm 5.9^{\mathrm{a}}$ \\
Off taste (mm) & $29.0 \pm 8.1$ & $32.5 \pm 8.1$ & $25.9 \pm 7.7$ & $24.8 \pm 7.0$ \\
Smell (mm) & $52.0 \pm 6.8$ & $42.0 \pm 6.9$ & $43.7 \pm 6.5$ & $40.1 \pm 5.9$ \\
Palatability (mm) & $43.7 \pm 6.4$ & $45.6 \pm 6.4$ & $36.1 \pm 6.1$ & $33.7 \pm 5.5$ \\
\hline
\end{tabular}

${ }^{1}$ Data are presented as means \pm SE. Data was analyzed using linear mixed models with meal as fixed effect, adjusted for sex, age, BMI, and visit number. $100 \mathrm{~mm}$ represent the most negative evaluation. Values sharing a common letter are significantly different. mm, millimeters; SM, salmon and mashed potatoes; SP, salmon and pasta; $\mathrm{VM}$, veal and mashed potatoes; VP, veal and pasta. 


\subsection{Wel-Bleing and Gastrointestinal Side Effects}

There were no differences in the evaluation of well-being between the test meals $(p=0.35)$ or in the incidence of gastrointestinal side effects (all $p>0.05$ ).

\section{Discussion}

The current study showed a higher DIT after a meal with salmon and high GI carbohydrates compared to a meal with salmon and low GI carbohydrates. Thus, we were unable to confirm our hypothesis that the meal with salmon in combination with low GI carbohydrates would increase DIT compared to the salmon meal with high GI carbohydrates and the veal meals with carbohydrates with low or high GI. The higher DIT after the salmon meal with high GI carbohydrates compared with the salmon meal with low GI carbohydrates, but not after the veal meal with high GI carbohydrates compared to the veal meal with low GI carbohydrates, indicates that the GI is not responsible for the observed difference per se. The difference must, therefore, be a combined effect of salmon and the high GI carbohydrates. We observed that the total plasma amino acid concentration peaked significantly faster after the salmon meal with high GI carbohydrates compared with the salmon and veal meals in combination with low GI carbohydrates. This indicates more rapid digestion of the proteins and/or uptake of amino acids in the salmon meal with high GI carbohydrates. Rapidly digested proteins have been shown to increase DIT compared with more slowly digested proteins, probably mediated by an increased postprandial protein synthesis [33,34]. Additionally, the salmon meal with high GI carbohydrates resulted in a higher plasma concentration of the branched-chain amino acid leucine compared to the meals with salmon or veal in combination with low GI carbohydrates. High plasma concentrations of leucine have been shown to enhance the rate of postprandial protein synthesis, and leucine has, in addition, been shown to be more thermogenic than other amino acids in rats [35,36]. Thus, differences in the rate of postprandial protein synthesis after the four meals may in part explain the difference in DIT observed in the present study.

We found differences in carbohydrate oxidation between the meals. The differences within the salmon and veal meals were dependent on the GI of the carbohydrates with the meals, with a high GI resulting in increased carbohydrate oxidation. Conversely, fat oxidation was higher after ingestion of the meals with low GI. Fat oxidation was, furthermore, higher after the salmon meals compared with the veal meals in combination with the same GI of the accompanying carbohydrates. It has been hypothesized that high-GI meals compared with low-GI meals increase carbohydrate oxidation and reduce fat oxidation [16]. Our results confirm this hypothesis, which is also supported by some previous studies [20,37]. However, it has not been shown consistently, and several studies have not found any differences in substrate oxidation between meals with low or high GI carbohydrates [16-19].

After both salmon meals, an increase in postprandial TAG concentration was found. This is in agreement with results from previous acute studies which, opposed to studies of longer durations, have shown higher TAG responses after meals rich in n-3 PUFAs compared to meals low in n-3 PUFAs [38-40]. Robertson et al. observed, additionally, a more rapid gastric emptying after a meal rich in n-3 PUFAs compared with meals rich in saturated fatty acids, monounsaturated fatty acids, or n-6 PUFAs [38]. Thus, it is possible that the elevated postprandial TAG response after the salmon meals could be a result of a more rapid gastric emptying.

In the current study, we did not observe differences in satiety, hunger, fullness, or ad libitum EI between the test meals. However, PFC was lower after the salmon meal with high GI carbohydrates compared with the veal meal with low GI carbohydrates. Protein from different fish species such as ling fish, tuna, cod, and antarcticus has previously been shown to increase satiety compared with protein from animal sources $[5,7,8]$. Uhe et al. found increased satiety after consumption of fish (mustelus antarcticus) compared to beef and chicken [5]. The authors observed that plasma amino acids took significantly longer time to peak after consumption of fish. They suggest that this may have been a result of slower digestion, slower gastric emptying, or slower absorption after fish, and that this could be related to the beneficial effect of fish on appetite regulation. In the current study, we 
investigated time to peak of the total concentration of plasma amino acids, and found a faster time to peak after the salmon meal with high GI carbohydrates compared with the meals with salmon or veal and low GI carbohydrates. In contrast to the study by Uhe et al. PFC was lowest after the meal with the fastest peak of total amino acids, which does not comply with the suggested decrease in appetite after slowly absorbed proteins [5]. Furthermore, differences in time to peak between the test meals in this present study did not influence satiety, hunger, fullness, or EI and were not dependent on protein source per se, but rather a combined effect of protein source and type of carbohydrate.

We found a difference in ghrelin levels between the meals. The ghrelin levels were generally suppressed after the salmon meals compared to the veal meals. Plasma ghrelin levels have, in obese women, previously been demonstrated to be reduced after a high-fat meal with PUFA compared to a high-fat meal with saturated fatty acids [41]. Thus, the differences in ghrelin levels between the salmon and veal meals could be a result of the differences in fatty acid composition.

We found that differences in serum insulin seemed to reflect the GI of the carbohydrates regardless of protein source. However, serum insulin concentrations did not reflect the differences in plasma glucose concentrations as the salmon meals induced lower glucose peaks compared to the veal meals in combination with the same GI of the accompanying carbohydrates. Thus, our data demonstrate that the combination of foods in mixed meals influences postprandial glucose regulation. This might be of importance in subjects with impaired ability to control blood glucose as larger fluctuations in blood glucose are unwanted. The long chain n-3 PUFA could be speculated to influence the postprandial glucose response. Some authors have demonstrated that the addition of unsaturated fat to carbohydrates resulted in a lower glucose response compared to the addition of saturated fat $[42,43]$, although this has not been shown consistently [44-46]. Different proteins may also affect the glycemic response differently. It is known that some amino acids stimulate insulin secretion and promote glucose uptake [47]. However, our results suggest an insulin-independent effect of salmon on plasma glucose. It could, additionally, be speculated that impaired glucose absorption from the intestines or increased storage of the glucose in the liver as glycogen could be responsible for the difference in postprandial glucose response. However, the higher DIT and carbohydrate oxidation after the SM meal (and partly the VM meal) indicates that glucose is taken up in tissues and used as energy substrate through glycolysis.

\subsection{Strengths and Limitations}

The current study has both strengths and limitations, which should be taken into account. The strengths included the randomized crossover study design, our thorough standardization, and the use of the protein sources in real meals with low and high GI, which made it possible to investigate the influence of the accompanying carbohydrates. Based on the Danish dietary software program Dankost $3000^{\circledR}$ (Dansk Catering Center, Copenhagen, Denmark), the test meals were iso-caloric and macronutrient-balanced, and had the same weight and fiber content. However, laboratory analysis of the amino acid composition of the meals revealed the meals with salmon had an approximately $4.5 \mathrm{~g}$ lower protein content than the calculated content. The protein content in the veal meals was consistent with the calculated value. Discrepancies may be a result of the analytical method used to determine protein content in foods. Data in Dankost $3000^{\circledR}$ are based on data from the Danish food composition database. Here, the protein content is based on an analysis of total nitrogen content; the nitrogen content is then multiplied by a factor of 6.25 to calculate protein content [48]. However, salmon and seafood have, in general, a relatively high amount of non-protein nitrogen-compounds compared with land animals [49]. Consequently, the protein content of seafood may be estimated to be higher than the actual amount [49]. This is problematic and a weakness of the present study. However, it nonetheless emphasizes the importance of analyzing the actual meal composition. Further weaknesses of the current study includes the small subsample of five participants for the analyses of plasma amino acids and the limitations of the NMR method for amino acid analyses, which was unable to detect 
cysteine and tryptophan as they were below limit of detection. Consequently, total plasma amino acid concentrations were based on the sum of plasma amino acids without these two amino acids.

\subsection{Conclusions}

In conclusion, salmon with high GI carbohydrates increased DIT compared to macronutrient-balanced meals with salmon and low GI carbohydrates, whereas no difference was found in comparisons with meals with veal and high or low GI carbohydrates. This finding indicates a combined effect of salmon and high GI carbohydrate on DIT. We propose that an earlier plasma amino acid peak after the meal with salmon and high GI carbohydrates compared with the meal with salmon and low GI carbohydrates could be responsible for the higher DIT. Protein from salmon and veal did not influence appetite sensations or energy intake differently. However, the appetite response may be influenced by the combination of protein source and GI, as a difference was seen in prospective food consumption between the meal with salmon and high GI carbohydrates compared with the meal with veal and low GI carbohydrates.

Supplementary Materials: The following are available online at www.mdpi.com/2072-6643/11/2/365/s1, Figure S1: Mean unadjusted 200 min changes in serum C-peptide and plasma lactate, Table S1: Measurements in the study, Table S2: Differences between the four test meals in plasma amino acids concentrations.

Author Contributions: Conceptualization, L.K., B.L., K.K., L.M., and A.R.; Methodology, S.N., L.K., U.K.S., H.C.B., M.S.W.-P., B.L., K.K., L.M., and A.R.; Validation, S.N., L.K., L.V.N., and A.R.; Formal analysis, L.V.N. and C.R.; Investigation, L.V.N. and S.N.; resources, U.K.S. and H.C.B.; Data curation, L.V.N. and S.N.; Writing - original draft, L.V.N.; writing_-review and editing, L.V.N.; visualization, L.V.N. and S.N.; supervision, A.R.; Project administration, S.N., L.K. and A.R.; funding acquisition, A.R. All authors participated in the discussion of the results, reviewed the manuscript and approved the final manuscript.

Funding: This research was funded by the Norwegian Seafood research fund (FINS 900842).

Acknowledgments: We gratefully acknowledge Janne Kunchel, Søren Andresen, Eivind Bjørås, John Gargul Lind, Charlotte Kostecki, and Karina Graff Rossen at the Department of Nutrition, Exercise, and Sports, University of Copenhagen.

Conflicts of Interest: The authors declare no conflicts of interest.

\section{References}

1. Belza, A.; Ritz, C.; Sørensen, M.Q.; Holst, J.J.; Rehfeld, J.F.; Astrup, A. Contribution of gastroenteropancreatic appetite hormones to protein-induced satiety. Am. J. Clin. Nutr. 2013, 97, 980-989. [CrossRef] [PubMed]

2. Hochstenbach-Waelen, A.; Westerterp-Plantenga, M.S.; Veldhorst, M.A.B.; Westerterp, K.R. Single-protein casein and gelatin diets affect energy expenditure similarly but substrate balance and appetite differently in adults. J. Nutr. 2009, 139, 2285-2292. [CrossRef] [PubMed]

3. Lejeune, M.P.; Westerterp, K.R.; Adam, T.C.; Luscombe-Marsh, N.D.; Westerterp-Plantenga, M.S. Ghrelin and glucagon-like peptide 1 concentrations, 24-h satiety, and energy and substrate metabolism during a high-protein diet and measured in a respiration chamber. Am. J. Clin. Nutr. 2006, 83, 89-94. [CrossRef] [PubMed]

4. Smeets, A.J.; Soenen, S.; Luscombe-Marsh, N.D.; Ueland, Ø.; Westerterp-Plantenga, M.S. Energy expenditure, satiety, and plasma ghrelin, glucagon-like peptide 1, and peptide tyrosine-tyrosine concentrations following a single high-protein lunch. J. Nutr. 2008, 138, 698-702. [CrossRef] [PubMed]

5. Uhe, A.M.; Collier, G.R.; O'Dea, K. A comparison of the effects of beef, chicken and fish protein on satiety and amino acid profiles in lean male subjects. J. Nutr. 1992, 122, 467-472. [CrossRef] [PubMed]

6. Holt, S.H.; Miller, J.C.; Petocz, P.; Farmakalidis, E. A satiety index of common foods. Eur. J. Clin. Nutr. 1995, 49, 675-690. [PubMed]

7. Pal, S.; Ellis, V. The acute effects of four protein meals on insulin, glucose, appetite and energy intake in lean men. Br. J. Nutr. 2010, 104, 1241-1248. [CrossRef]

8. Borzoei, S.; Neovius, M.; Barkeling, B.; Teixeira-Pinto, A.; Rössner, S. A comparison of effects of fish and beef protein on satiety in normal weight men. Eur. J. Clin. Nutr. 2006, 60, 897-902. [CrossRef] 
9. Kristensen, M.D.; Bendsen, N.T.; Christensen, S.M.; Astrup, A.; Raben, A. Meals based on vegetable protein sources (beans and peas) are more satiating than meals based on animal protein sources (veal and pork) - a randomized cross-over meal test study. Food Nutr. Res. 2016, 60, 32634. [CrossRef]

10. Soucy, J.; Leblanc, J. Protein Meals and Postprandial Thermogenesis. Physiol. Behav. 1998, 65, 705-709. [CrossRef]

11. Nielsen, L.; Kristensen, M.; Klingenberg, L.; Ritz, C.; Belza, A.; Astrup, A.; Raben, A. Protein from Meat or Vegetable Sources in Meals Matched for Fiber Content has Similar Effects on Subjective Appetite Sensations and Energy Intake-A Randomized Acute Cross-Over Meal Test Study. Nutrients 2018, 10, 96. [CrossRef] [PubMed]

12. Nielsen, L.V.; Nyby, S.; Klingenberg, L.; Juul-Hindsgaul, N.; Rudnicki, J.; Ritz, C.; Liaset, B.; Kristiansen, K.; Madsen, L.; Raben, A. Meals based on cod or veal in combination with high or low glycemic index carbohydrates did not affect diet-induced thermogenesis, appetite sensations, or subsequent energy intake differently. Appetite 2018, 130, 199-208. [CrossRef] [PubMed]

13. Nordic Council of Ministers. Nordic Nutrition Recommendations 2012: Integrating nutrition and physical activity. 2014, 5.

14. Martens, M.J.I.; Lemmens, S.G.T.; Born, J.M.; Westerterp-Plantenga, M.S. A Solid High-Protein Meal Evokes Stronger Hunger Suppression Than a Liquefied High-Protein Meal. Obesity 2011, 19, 522-527. [CrossRef] [PubMed]

15. Jenkins, D.J.; Wolever, T.M.; Taylor, R.H.; Barker, H.; Fielden, H.; Baldwin, J.M.; Bowling, A.C.; Newman, H.C.; Jenkins, A.L.; Goff, D.V. Glycemic index of foods: A physiological basis for carbohydrate exchange. Am. J. Clin. Nutr. 1981, 34, 362-366. [CrossRef] [PubMed]

16. Díaz, E.; Galgani, J.; Aguirre, C.; Atwater, I.; Burrows, R. Effect of glycemic index on whole-body substrate oxidation in obese women. Int. J. Obes. 2005, 29, 108-114. [CrossRef]

17. Keogh, J.B.; Lau, C.W.H.; Noakes, M.; Bowen, J.; Clifton, P.M. Effects of meals with high soluble fibre, high amylose barley variant on glucose, insulin, satiety and thermic effect of food in healthy lean women. Eur. J. Clin. Nutr. 2007, 61, 597-604. [CrossRef]

18. Scazzina, F.; Rio, D. Del; Benini, L.; Melegari, C.; Pellegrini, N.; Marcazzan, E.; Brighenti, F. The effect of breakfasts varying in glycemic index and glycemic load on dietary induced thermogenesis and respiratory quotient. Metab. Cardiovasc. Dis. 2011, 21, 121-125. [CrossRef]

19. Krog-Mikkelsen, I.; Sloth, B.; Dimitrov, D.; Tetens, I.; Björck, I.; Flint, A.; Holst, J.J.; Astrup, A.; Elmståhl, H.; Raben, A. A low glycemic index diet does not affect postprandial energy metabolism but decreases postprandial insulinemia and increases fullness ratings in healthy women. J. Nutr. 2011, 141, 1679-1684. [CrossRef]

20. Kaur, B.; Quek Yu Chin, R.; Camps, S.; Henry, C.J. The impact of a low glycaemic index (GI) diet on simultaneous measurements of blood glucose and fat oxidation: A whole body calorimetric study. J. Clin. Transl. Endocrinol. 2016, 4, 45-52. [CrossRef]

21. Hao, Q.; Lillefosse, H.H.; Fjaere, E.; Myrmel, L.S.; Midtbø, L.K.; Jarlsby, R.H.; Ma, T.; Jia, B.; Petersen, R.K.; Sonne, S.B.; et al. High-glycemic index carbohydrates abrogate the antiobesity effect of fish oil in mice. Am. J. Physiol. Endocrinol. Metab. 2012, 302, E1097-E1112. [CrossRef] [PubMed]

22. Raben, A. Should obese patients be counselled to follow a low-glycaemic index diet? No. Obes. Rev. 2002, 3 , 245-256. [CrossRef] [PubMed]

23. Bornet, F.R.J.; Jardy-Gennetier, A.-E.; Jacquet, N.; Stowell, J. Glycaemic response to foods: Impact on satiety and long-term weight regulation. Appetite 2007, 49, 535-553. [CrossRef] [PubMed]

24. Sun, F.-H.; Li, C.; Zhang, Y.-J.; Wong, S.; Wang, L. Effect of Glycemic Index of Breakfast on Energy Intake at Subsequent Meal among Healthy People: A Meta-Analysis. Nutrients 2016, 8, 37. [CrossRef] [PubMed]

25. Flint, A.; Raben, A.; Blundell, J.E.; Astrup, A. Reproducibility, power and validity of visual analogue scales in assessment of appetite sensations in single test meal studies. Int. J. Obes. Relat. Metab. Disord. 2000, 24, 38-48. [CrossRef] [PubMed]

26. Atkinson, F.S.; Foster-Powell, K.; Brand-Miller, J.C. International tables of glycemic index and glycemic load values: 2008. Diabetes Care 2008, 31, 2281-2283. [CrossRef]

27. Tastesen, H.S.; Keenan, A.H.; Madsen, L.; Kristiansen, K.; Liaset, B. Scallop protein with endogenous high taurine and glycine content prevents high-fat, high-sucrose-induced obesity and improves plasma lipid profile in male C57BL/6J mice. Amino Acids 2014, 46, 1659-1671. [CrossRef] 
28. Elia, M.; Livesey, G. Energy expenditure and fuel selection in biological systems: The theory and practice of calculations based on indirect calorimetry and tracer methods. World Rev. Nutr. Diet. 1992, 70, 68-131.

29. Abumrad, N.N.; Rabin, D.; Diamond, M.P.; Lacy, W.W. Use of a heated superficial hand vein as an alternative site for the measurement of amino acid concentrations and for the study of glucose and alanine kinetics in man. Metabolism 1981, 30, 936-940. [CrossRef]

30. Research Randomizer. Available online: https://www.randomizer.org/ (accessed on 6 February 2018).

31. Lorenzen, J.; Frederiksen, R.; Hoppe, C.; Hvid, R.; Astrup, A. The effect of milk proteins on appetite regulation and diet-induced thermogenesis. Eur. J. Clin. Nutr. 2012, 66, 622-627. [CrossRef]

32. Hothorn, T.; Bretz, F.; Westfall, P. Simultaneous Inference in General Parametric Models. Biom. J. 2008, 50, 346-363. [CrossRef] [PubMed]

33. Boirie, Y.; Dangin, M.; Gachon, P.; Vasson, M.P.; Maubois, J.L.; Beaufrère, B. Slow and fast dietary proteins differently modulate postprandial protein accretion. Proc. Natl. Acad. Sci. USA 1997, 94, 14930-14935. [CrossRef] [PubMed]

34. Acheson, K.J.; Blondel-Lubrano, A.; Oguey-Araymon, S.; Beaumont, M.; Emady-Azar, S.; Ammon-Zufferey, C.; Monnard, I.; Pinaud, S.; Nielsen-Moennoz, C.; Bovetto, L. Protein choices targeting thermogenesis and metabolism. Am. J. Clin. Nutr. 2011, 93, 525-534. [CrossRef] [PubMed]

35. Wall, B.T.; Hamer, H.M.; de Lange, A.; Kiskini, A.; Groen, B.B.L.; Senden, J.M.G.; Gijsen, A.P.; Verdijk, L.B.; van Loon, L.J.C. Leucine co-ingestion improves post-prandial muscle protein accretion in elderly men. Clin. Nutr. 2013, 32, 412-419. [CrossRef] [PubMed]

36. Tsujinaka, T.; Sakaue, M.; Iijima, S.; Ebisui, C.; Kan, K.; Kishibuchi, M.; Morimoto, T.; Kido, Y. Modulation of thermogenic response to parenteral amino acid infusion in surgical stress. Nutrition 1996, 12, 36-39. [CrossRef]

37. Camps, S.G.; Kaur, B.; Quek, R.Y.C.; Henry, C.J. Does the ingestion of a 24 hour low glycaemic index Asian mixed meal diet improve glycaemic response and promote fat oxidation? A controlled, randomized cross-over study. Nutr. J. 2017, 16, 43. [CrossRef] [PubMed]

38. Robertson, M.D.; Jackson, K.G.; Fielding, B.A.; Morgan, L.M.; Williams, C.M.; Frayn, K.N. Acute ingestion of a meal rich in n-3 polyunsaturated fatty acids results in rapid gastric emptying in humans. Am. J. Clin. Nutr. 2002, 76, 232-238. [CrossRef]

39. Griffo, E.; Di Marino, L.; Patti, L.; Bozzetto, L.; Annuzzi, G.; Cipriano, P.; Mangione, A.; Della Pepa, G.; Cocozza, S.; Riccardi, G.; et al. Test meals rich in marine long-chain n-3 polyunsaturated fatty acids increase postprandial chylomicron response. Nutr. Res. 2014, 34, 661-666. [CrossRef]

40. Roche, H.M.; Gibney, M.J. Effect of long-chain $n-3$ polyunsaturated fatty acids on fasting and postprandial triacylglycerol metabolism. Am. J. Clin. Nutr. 2000, 71, 232s-237s. [CrossRef] [PubMed]

41. Stevenson, J.L.; Clevenger, H.C.; Cooper, J.A. Hunger and satiety responses to high-fat meals of varying fatty acid composition in women with obesity. Obesity (Silver Spring) 2015, 23, 1980-1986. [CrossRef]

42. Gatti, E.; Noè, D.; Pazzucconi, F.; Gianfranceschi, G.; Porrini, M.; Testolin, G.; Sirtori, C.R. Differential effect of unsaturated oils and butter on blood glucose and insulin response to carbohydrate in normal volunteers. Eur. J. Clin. Nutr. 1992, 46, 161-166. [PubMed]

43. Dworatzek, P.D.N.; Hegele, R.A.; Wolever, T.M.S. Postprandial lipemia in subjects with the threonine 54 variant of the fatty acid-binding protein 2 gene is dependent on the type of fat ingested. Am. J. Clin. Nutr. 2004, 79, 1110-1117. [CrossRef] [PubMed]

44. Henry, C.J.K.; Lightowler, H.J.; Newens, K.J.; Pata, N. The influence of adding fats of varying saturation on the glycaemic response of white bread. Int. J. Food Sci. Nutr. 2008, 59, 61-69. [CrossRef] [PubMed]

45. MacIntosh, C.G.; Holt, S.H.A.; Brand-Miller, J.C. The degree of fat saturation does not alter glycemic, insulinemic or satiety responses to a starchy staple in healthy men. J. Nutr. 2003, 133, 2577-2580. [CrossRef] [PubMed]

46. Sun, L.; Tan, K.W.J.; Lim, J.Z.; Magkos, F.; Henry, C.J. Dietary fat and carbohydrate quality have independent effects on postprandial glucose and lipid responses. Eur. J. Nutr. 2018, 57, 243-250. [CrossRef] [PubMed]

47. Jahan-Mihan, A.; Luhovyy, B.L.; El Khoury, D.; Anderson, G.H. Dietary proteins as determinants of metabolic and physiologic functions of the gastrointestinal tract. Nutrients 2011, 3, 574-603. [CrossRef] [PubMed] 
48. Fødevareinstituttet, D.T.U. Frida Fødevaredata. Version 2. 2016. Available online: https://frida.fooddata.dk (accessed on 14 March 2018).

49. Salo-Viiiinhen, P.P.; Koivistoinen, P.E. Determination of protein in foods: Comparison of net protein and crude protein (Nx 6.25) values. Food Chembtry 1996, 51, 21-31.

(c) 2019 by the authors. Licensee MDPI, Basel, Switzerland. This article is an open access article distributed under the terms and conditions of the Creative Commons Attribution (CC BY) license (http://creativecommons.org/licenses/by/4.0/). 